\title{
1. Improving the wellbeing of Australian children and youth: the importance of bridging the know-do gap
}

\author{
Ann Sanson and Fiona Stanley
}

\section{Introduction}

This chapter seeks to place the need for knowledge sharing in the context of children and youth growing up in Australia today. We present evidence of the disturbing lack of progress in improving the life chances of our young people, including continuing if not accelerating socio-demographic inequalities, and describe how a determination to address these issues led to the creation of the Australian Research Alliance for Children and Youth (ARACY). We emphasise the critical importance of an evidence-based approach to policy and practice in improving children's life chances and describe some of the obstacles to the uptake of knowledge, such as the ubiquitous 'silo' mentality and rigid organisational structures. We then highlight some instances where available knowledge is not being fully applied. For example, we know that prevalent problems such as child abuse and neglect are the result of a complex set of causal factors and that we will never have the capacity to provide effective responses to all children and youth affected by them. This leads to the conclusion that we must shift the emphasis to prevention and early intervention. Yet, the majority of resources continue to be channelled into responding to the problems rather than their causes. We end by describing some of ARACY's recent initiatives, which are aimed at advancing our capacity to use knowledge to improve the health, development and wellbeing of children and youth. 


\section{Child and youth wellbeing in twenty-first- century Australia}

Australia's wealth as a nation has increased markedly over the past 30 years - a period that has also seen a number of major social changes that have influenced the context in which children grow to adulthood. These changes include

- greater workforce participation by women with children (and a concomitant increase in non-parental child care)

- changes in work mobility and reductions in job security

- increased rates of divorce and single parenthood, now experienced by more than one-quarter of all children

- women having children at an older age

- an ageing population

- changes in welfare and social security policy

- the extraordinary transformations in information technology.

In themselves, these changes do not inevitably lead to negative outcomes for children. In this era of relative overall prosperity, however, we would do well to ask whether children and young people are 'having the time of their lives' or are 'struggling with life in their times' (Eckersley 2004).

Sadly, during this same period, there have been substantial increases in many major childhood disease categories and disabilities, including mental health disorders, Type 1 diabetes, obesity, behavioural problems and neurological and developmental problems such as cerebral palsy and autism. For example, the child and youth component of the National Survey of Mental Health and Wellbeing (Sawyer et al. 2001) found that one in six children aged four to twelve years had some type of mental health problem that interfered with their daily life. Trends in pre-term births are increasing, with much of low birth weight and pre-term birth arising in social adversity. The Australian Institute for Health and Welfare's 2007 report, Young Australians: Their health and wellbeing, noted that mental health problems and obesity have increased among young people aged fifteen to twenty-four in recent years, as have rates of sexually transmitted infections such as chlamydia and gonococcal infection. In 2004, almost one-third of young people drank alcohol at high-risk levels and about 17 per cent were current smokers. The suicide rate among young men has quadrupled, and for young women has doubled, in the past 30 years. There are similar increases in educational problems, the incidence of substance abuse and juvenile crime rates. The 2006 Census indicated that more than 12000 children were homeless - an increase of 22 per cent from the 2001 Census (ABS 2008). Notifications and substantiations for child abuse and neglect have risen 
so markedly that the child protection system is under severe stress; in the past five years, child protection notifications have almost doubled; the number of children on care and protection orders increased by 32 per cent and numbers in out-of-home care increased by 35 per cent between 2002 and 2006 (see ARACY and The Allen Consulting Group 2008).

Further, there are strong socioeconomic gradients that indicate an uneven distribution of these problem outcomes. For example, recent analyses of Waves 1 and 2 of the Longitudinal Study of Australian Children (Smart et al. 2008) showed that four to five-year-old children from financially disadvantaged families were approximately twice as likely to be 'unready' for school in terms of their social, emotional, language and cognitive development compared with other children. They were also at close to twice the risk of poor progress in their first two years of school. Overall, 43 per cent of disadvantaged children contended with five or more risk factors likely to compromise their development - compared with only 14 per cent of other children.

Australia's international standing on child and youth wellbeing is not strong. ARACY's Report Card on the Wellbeing of Young Australians (2008) examined Australia's standing in comparison with other Organisation for Economic Cooperation and Development (OECD) countries on eight domains of child and youth wellbeing, where internationally comparable data were available. Australia was not a leader in any domain and was generally in the bottom half or third of countries with comparable data. For example, Australia ranked twentieth out of 27 countries on infant mortality, seventh out of eight on accidental injury and twenty-first out of 30 in teenage fertility. The recent UNICEF report The Child Care Transition (2008) indicated the dire state of childcare funding and infrastructure in Australia, finding that ours was the third-worst childcare and early learning system in the developed world. Another UNICEF report, Child Poverty in Perspective (2007), found that, while Australia was about average relative to other OECD countries on some indicators of material and educational wellbeing and health and safety, it was second only to Hungary in the percentage of children living in jobless households and ranked low on other measures such as family structure, child-parent interaction and peer relationships.

ARACY's report card also paints a stark picture of the wellbeing of Aboriginal and Torres Strait Islander ${ }^{1}$ children and youth compared with Australians overall and with other OECD countries. In many domains, their indicators were as bad or worse than the lowest of the OECD countries - for example, material deprivation (ranked 29 of 31 countries), infant mortality (26/28), low birth weight (19/19), mental health problems (23/24), school achievement (29/31), sense of belonging at school (29/30) and teenage fertility (31/31). While Aboriginal people make

1 Referred to from now on as Aboriginal. 
up 2 per cent of the total population, they make up 9 per cent of those who are homeless and 19 per cent of those in improvised housing (MacKenzie and Chamberlain 2003). They have more than twice the rate of hospitalisations for asthma and diabetes and five times the rate of child protection substantiations (AIHW 2008). Data from the Longitudinal Study of Australian Children show that the gap between Aboriginal and non-Aboriginal children's development widens markedly from infancy to four-five years of age. Despite few differences in infancy, by four-five years of age, Aboriginal children on average were lower in all aspects of development except physical development (Sanson 2005). These data point to the importance of factors in Aboriginal children's child-rearing environments in explaining the decline in wellbeing over time.

In summary, despite our relative economic prosperity, there are many areas where the situation for children and youth has failed to improve and in too many instances it is in fact deteriorating. Social inequalities remain entrenched and could be increasing.

ARACY was formed because of shared concern about these unacceptable statistics. It brings together researchers, policymakers and service providers from diverse backgrounds from across Australia to work together to improve the wellbeing of children and young people. It seeks to encourage and support a collaborative, cross-disciplinary and cross-sectoral approach to increase effectiveness in tackling the complex problems facing children and youth. Many of these are 'wicked' problems, which are not amenable to 'quick fixes'. Enhancing our capacity to use evidence effectively to guide policy and practice is thus a key ingredient to progress. This book, and the national symposium from which it is derived, forms part of ARACY's efforts to encourage evidencebased policy and practice (see Introduction).

\section{The case for evidence-based policy and practice}

Implementing evidence-based policy and practice is foundational to ARACY's vision for improving child and youth wellbeing. It is widely acknowledged that high-quality research is needed to support effective government decision making (see The British Academy 2008). For example, governments need evidence to determine what options will 'deliver the goods' and provide best 'value for money' and what policies are likely to promote innovation and achieve best outcomes for stakeholders (see Head, this volume). In relation to practice, taking an evidence-based approach - the conscientious, explicit, judicious use of current best evidence in making decisions' (Sackett et al. 1996) - is a 
matter of accountability and quality. It helps to ensure that scarce taxpayer or donated dollars are spent equitably and only on interventions of demonstrable and demonstrated worth (Spring 2007).

The shared frustrations over the persistence of 'wicked' problems such as poverty, child abuse, substance abuse and Aboriginal disadvantage that drove the formation of ARACY are matched by widespread frustration at the failure of much policy and practice to reflect the evidence base. There are missed opportunities for knowledge exchange and for research-based data to play the part they should in decisions over policy and interventions (The British Academy 2008).

Stone (2002) discusses the demand-side, supply-side and socio-cultural factors that create obstacles to the uptake of knowledge. Demand-side issues include a lack of awareness of the existence or relevance of research and limited interest in and/or capacity to absorb and use research knowledge. If policymakers and practitioners do not believe that attention to research evidence will result in better policy and practice, it will not be acted upon. Landry et al. (2003) similarly identify the valuing of research knowledge as the first of the factors leading to successful knowledge translation.

Given the demands on policymakers and their high levels of mobility, it is often difficult for them to master the evidence about the complex problems facing our children and youth. Often, the research points to multiple causal influences and long-term strategies such as prevention and early intervention where the benefits might not appear for many years - well beyond a budgetary cycle or term of government. Further, the benefits are often in portfolios other than those responsible for the initial policies or interventions. For example, the long-term benefits of the Perry Preschool Program for disadvantaged children in the United States appeared in areas such as finance (because recipients of the program held better-paying jobs and hence paid more tax), the criminal justice system (with fewer convictions and incarcerations), the education system (fewer recipients needed special programs at school) and the health system (with better physical and mental health) (Schweinhart et al. 2005). More locally, installing swimming pools in remote Aboriginal communities has been shown to improve aspects of health, education and behaviour of Aboriginal children and youth over a six-year period. The costs of this intervention - the infrastructure for the pools and community engagement - were borne mainly by portfolios other than those benefiting from them (Lehmann et al. 2003). Without a cross-portfolio approach, it can be difficult for evidence to gain traction.

Further, a critical source of knowledge is the evaluation of programs, which can be threatening to both policymakers and service providers. The Australian child and youth arena is littered with unevaluated short-term 'pilot' programs. When 
faced with the latest in a long run of pilot programs, one remote Aboriginal community is known to have commented that they had 'a shed full of bomber jackets' from all the pilot programs that had 'flown in and flown out'. There are also continuing programs for which there is little evaluation data and, equally problematically, interventions whose funding is withdrawn despite positive evaluations. Even when programs have been shown to be effective in one context (for example, a program evaluated on suburban white Australians), we have a history of failure to deliver them effectively to disadvantaged groups. For example, evaluation has shown that traditional public health advice has failed to reduce sudden infant death syndrome (SIDS) and birth defects in Aboriginal communities (Freemantle et al. 2007; Bower et al. 2004), although participatory action research methods are now showing promising preliminary results for SIDS (Stanley, Personal communication).

Supply-side issues can apply to both researchers and practitioners. The recent UK government publication $A$ Vision for Science and Society argues that engaging with policymakers ought to be a valued part of what it is to be a scientist (Department for Innovation, Universities and Skills 2008), but most Australian research environments continue to place disincentives in the way of researchers who would like to engage in collaboration with people in other sectors for the purposes of knowledge exchange. Researchers often have poor understanding of the needs of policymakers and practitioners, such as their much tighter time lines. Ineffective communication by researchers to non-academic audiences is another limiting factor (Landry et al. 2003). The technical, lengthy and cautious modes of writing often adopted by researchers are not useful for policy and practice readers, who are time poor, do not share the same technical jargon and need the implications of the research to be clearly spelled out in short documents.

Perhaps the most important factors that can mitigate against the uptake of evidence in policy and practice are socio-cultural issues. The 'disconnect' between researchers, practitioners and policymakers, and between health, education, treasury/finance, welfare and other such sectors - where each sector operates in its own 'silo', speaks a different 'language', has different constraints and operates with different time frames - is widely acknowledged, but seldom addressed. This is compounded by the contested nature of 'knowledge' and 'evidence' in the social sciences, in comparison with medicine, where the concept of evidence-based practice has been accepted for many years (Goldfeld, this volume). When considering 'wicked' problems that have a complex set of causal factors ranging from 'upstream' influences such as social disadvantage and housing, through to 'downstream' factors such as parenting and teacherchild relationships, the 'knowledge' to be brokered or exchanged is likewise complex. 


\section{Complex causal pathways: some examples of failure to act on evidence}

This problem is becoming more pressing as the challenges facing society increasingly straddle the boundaries of a number of government departments and require inputs from experts in many disciplines (The British Academy 2008). The complexity of the influences on child and youth development is reflected in Bronfenbrenner's well-known bio-ecological systems theory of development (Bronfenbrenner and Morris 2006) (see Figure 1.1). At the centre is the individual child, with their own genetic and constitutionally based characteristics. The child is embedded in the micro-system, representing their immediate environments - for example, family, school, peer group - which are the 'downstream' influences on the child. The interactions among these microenvironments - for example, the nature of the connections between a child's home and school-form the meso-system and also impact on the child. The exo-system (external environmental settings, which indirectly affect the child, such as the parent's workplace) and macro-system (the larger cultural context such as economic and political systems and cultural beliefs) represent the more 'upstream' influences. Finally, the chrono-system reflects the patterning of environmental events and transitions over the course of life.

Figure 1.1 Representation of Bronfenbrenner's socio-ecological model of development with examples of factors within each system

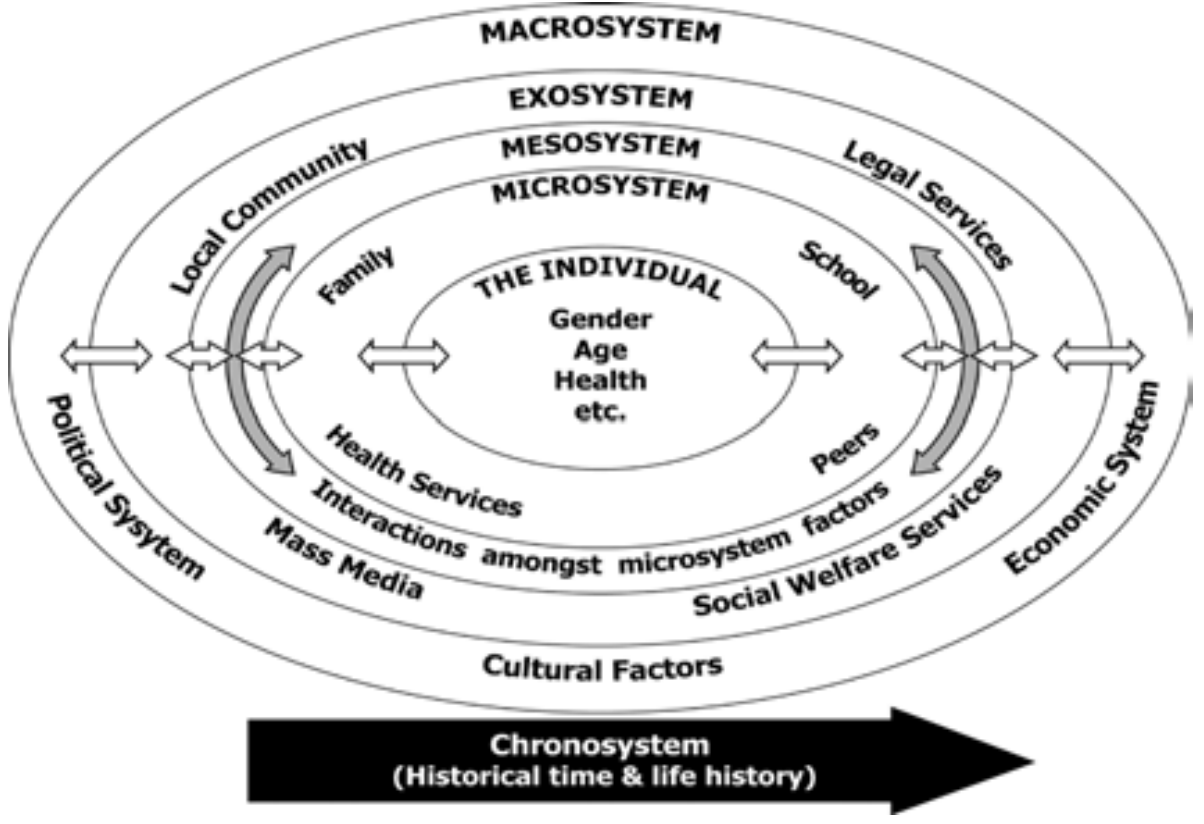


This conceptualisation of development has helped us understand 'developmental pathways' to various outcomes. Figure 1.2 is a schematic representation of the pathway to good educational outcomes, which illustrates that influences on the pathway start early in life but continue over time and are situated in each layer in Bronfenbrenner's model. Hence, there is a need for the engagement of many players in ensuring that children follow a positive pathway. If such pathways are not understood by decision makers, it can lead to attempts at 'quick fixes' addressing discrete influences at the end of developmental pathways - despite the fact that the evidence often suggests that they will be costly and relatively ineffective.

Figure 1.2 Key leverage points to improve educational outcomes

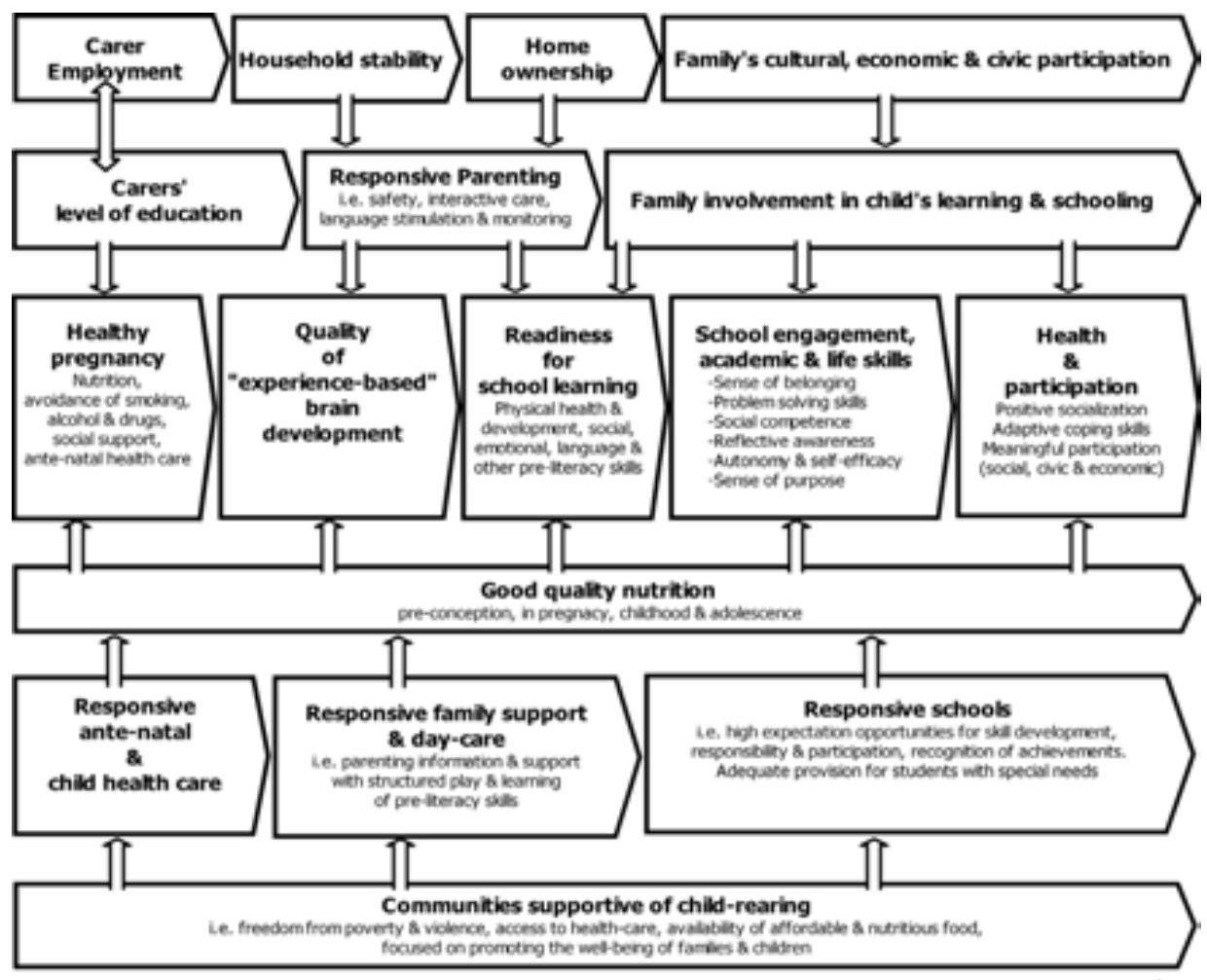

\section{Conception Birth School entry $1^{\circ} \& 2^{\circ}$ School Work force entry}

Adapted from Silburn (2009).

The current crisis in the child protection system is a good example of where we are witnessing the results of failure to address 'upstream' causal factors and where available knowledge is not being applied. Family disadvantage and instability, isolation and alienation, parental mental illness and substance abuse, lack of parenting skills as well as intergenerational factors are all known influences on 
the occurrence on child abuse and neglect; yet for at least a generation, the policy response to the problem of child abuse and neglect has been predominantly at the 'crisis' end, responding to allegations of abuse with measures that, intentionally or not, are punitive not only towards parents but also towards the children involved. Arguably policies have been driven too much by the imperative to save ministers from the political fallout if a child death or serious injury occurs. Services under pressure to deal with the overload of notifications do not have the resources to shift to a more preventive or supportive focus. The evidence is clear that children removed from families have far from optimal outcomes. The evidence-based alternative is to construct a multifaceted system that can provide a moderated response to all families' needs for support in order to prevent abuse and neglect in the first place, and to help those in greater need to develop their parenting abilities so that child removal becomes a rare event of last resort (O'Donnell et al. 2008). The Wood Report (Wood 2008:i) on the inquiry into the child protection system in New South Wales concluded that '[t]he contemporary challenge facing all child protection systems in Australia... is sufficiently resourcing flexible prevention and early intervention services so as to reduce the number of children and young people who require the state to step in to keep them safe', as well as integrated action to support those needing state intervention (see also ARACY and The Allen Consulting Group 2008). It is indeed encouraging that moves are now underway to reform the system to encompass integrated evidence-based prevention. For example, under the National Framework for Protecting Australia's Children 2009-2020 endorsed by the Council of Australian Governments (COAG), ARACY is co-convening a task force (with Minister Jenny Macklin) to develop a common approach to assessment, referral and support for vulnerable children and their families, in order to reduce the incidence of child abuse and neglect (the Common Approach to Assessment, Referral and Support (CAARS) Task Force).

The second example is what has become known as the 'Northern Territory intervention'. After years of paying scant attention to official and unofficial reports of distress and dysfunction in some Aboriginal communities, and of failure to provide adequate support for basic services such as health, policing and housing, the Federal Government 'discovered' the crisis in child abuse, neglect and ill health in 2006. An interesting analysis of how the issue came to policy prominence is provided by Moore (this volume). The response has been focused predominantly at the 'downstream' end of causal pathways, not their 'upstream' beginnings. While children's needs in the short term must obviously be addressed, long-term change requires attention to the drivers for strong family functioning, which include adequate housing and financial security, access to relevant education and meaningful occupation and their roots in community and cultural wellbeing. The intervention has paid little attention to the evidence of the importance of strong cultural continuity and community 
'ownership' of initiatives that comes from research overseas, such as Chandler's work on Aboriginal youth suicide in Canada (for example, Chandler et al. 2003), and local initiatives (Zubrick et al. 2005).

\section{ARACY's approach to overcoming the obstacles to knowledge sharing}

A recurring theme in the literature on evidence-based policy and practice is the need for better dialogue, partnerships and collaboration across sectors (for example, Nutley et al. 2007). As Farfard (2008) notes, the analysis and promotion of policy options form a process of facilitating conversations and dialogue between different participants in the policy process. Key factors leading to successful knowledge translation identified by Landry et al. (2003) include the strength of not only formal links between researchers and policy makers, but informal relationships characterised by respect and trust, and collaborative working relationships. Cashmore (2003) also argues for a more collaborative process between researchers, policymakers and practitioners in order to set the research agenda, interpret findings and work out the implications for policy and practice in relation to better outcomes for children. (She also argues for including children's voices in this process, since their perceptions have an important role to play in understanding the impact of policy and practice changes.)

Evidence is accumulating about ways to facilitate these closer relationships. For example, two-way secondments between academia, government and service-provider organisations can develop understandings and connections that support knowledge transfer and provide vital insights into the needs and constraints of each sector (for further discussion, see Michaux, this volume). The notion of unidirectional knowledge exchange, whereby knowledge is generated by researchers and drawn on by policy and practice, has proven to be overly simplistic and ineffective. The advantages of a process of co-production of knowledge that aims to dissolve the boundary between evidence producers and users are also being recognised. In co-production models, all stakeholders are engaged and brought together from the outset of the research and all forms of expertise - research, policy, practice, business, the media, and so on-are considered valuable inputs into knowledge innovation, knowledge production and knowledge transfer. There is evidence that involving research users throughout the entire research process in this way increases the impact and take-up of the findings (for example, RELU 2007).

ARACY uses its status as a 'boundary organisation' (see Introduction), spanning the traditional disciplinary and sectoral silos, to develop these ideas and apply them to stimulate a more evidence-based approach to tackling the 'big-picture' 
issues confronting children and youth. Its report card, previously mentioned, is one undertaking aimed at bringing evidence to the fore and using it as an impetus for action. Several other examples of ARACY's knowledge-sharing initiatives follow.

The first example is ARACY's Collaboration Program, in which it is working with researchers, practitioners and experts in a range of fields related to poverty, social inclusion, early childhood development and education as well as social entrepreneurship, business and other groups who can drive ideas into action. It has developed a model for collaboration that starts by commissioning a focusing paper that draws together current evidence on a topic. This is then used as a basis for national consultations and think tanks with practitioners, stakeholders and experts from all sectors around Australia, from which an agenda and concrete proposals for action are developed and a business case is prepared to secure resources for implementation. Examples of current collaboration projects are

- children's readiness to learn - aiming to identify the points of intervention where most benefit will be achieved in reducing the impact of poverty on children's ability to learn

- disengaged youth - a cross-sectoral collaborative project aimed at preventing aggressive and violent behaviour among young people

- measuring the outcomes of community organisations - focusing on measures of service quality, outcomes and effectiveness, and linking these to strategies that improve support for community service organisations.

In a second example, ARACY was commissioned by the Australian Government to provide support to the 45 Communities for Children Projects in disadvantaged areas across Australia. Projects were asked to identify areas where they needed access to the best evidence (for example, how to encourage community participation; what constitutes child-friendly communities and how are they built) and researchers were asked to synthesise knowledge in these areas into accessible, short topical papers and then to discuss key practice issues emerging from the evidence with the projects. To overcome the 'tyrannies of distance', these discussions were held as 'webinars' (web seminars), whereby project members even in remote locations could interact in real time using the Internet and teleconferencing.

The third example is the Seed-Funding Program run by the ARACY ARC/ NHMRC (Australian Research Council/National Health and Medical Research Council) Research Network. Recognising that time and resources are needed to develop relationships and mutual understanding between parties who have not previously worked together, this program has sought to build innovative sustainable cross-sectoral collaborations by offering seed funding on specified topic areas. These support collaborative teams to develop their project ideas to 
the stage where they can seek external funding. Over the four years to 2009, 51 projects have been supported, involving 542 collaborators. Evaluation has shown that the program is highly successful, leading to the development of national research agendas, sustainable cross-sectoral networks and useful resources. The program has already shown a strong return on investment in terms of successful research grants to allow projects to expand their work. The evaluation is also providing information on the factors that promote and impede successful collaborations.

Another initiative of the ARACY Research Network provides the fourth example. In order to build the capacity of the next generation of researchers to work together across disciplines and to engage in effective knowledge transfer, the Research Network has established the New Investigators Network. It currently consists of 20 high-calibre early career researchers and a team of senior mentors and advisers, who are using the Longitudinal Study of Australian Children dataset as a common base to develop collaborative projects on child and youth health and development. These young researchers are being groomed to be future research leaders who can interface with policy and practice more effectively.

Another approach to advancing our national capacity for sharing and using knowledge is to bring together those with expertise in knowledge brokering to share their experiences and then to capture them for others to learn from. Adopting this approach, the ARACY Research Network partnered with two of its member organisations to hold the national symposium on which this book is based.

\section{References}

Australian Bureau of Statistics (ABS) 2008, Australian Census Analytic Program: Counting the homeless, Australia 2006, cat. no. 2050.0, reissued 18 September 2008, Commonwealth of Australia, Canberra.

Australian Institute for Health and Welfare (AIHW) 2007, Young Australians: Health and wellbeing 2007, Australian Institute of Health and Welfare, Canberra.

Australian Institute for Health and Welfare (AIHW) 2008, Child Protection Australia 2006-07, Child Welfare Series no. 43, Australian Institute for Health and Welfare, Canberra, viewed 3 May 2010, <http://www.aihw.gov. au/publications/cws/cpa06-07/cpa06-07-20080229.pdf> 
Australian Research Alliance for Children and Youth (ARACY) 2008, Report Card on the Wellbeing of Young Australians, Australian Research Alliance for Children and Youth, Canberra.

Australian Research Alliance for Children and Youth (ARACY) and The Allen Consulting Group 2008, Inverting the Pyramid: Enhancing systems for protecting children, The Allen Consulting Group, Melbourne.

Bower, C., Eades, S., Payne, J., D'Antoine, H. and Stanley, F. 2004, 'Trends in neural tube defects in Western Australia in Indigenous and non-Indigenous populations', Paediatric and Perinatal Epidemiology, vol. 18, pp. 277-80.

Bronfenbrenner, U. and Morris, P. A. 2006, 'The bioecological model of human development', in W. Damon and R. M. Lerner (eds), Handbook of Child Psychology. Volume 1, John Wiley \& Sons, New York, pp. 793-828.

Cashmore, J. 2003, 'Children's participation in family law matters', in C. Hallett and A. Prout (eds), Hearing the Voices of Children: Social policy for a new century, Falmer Press, London.

Chandler, M. J., Lalonde, C., Sokol, B. and Hallett, D. 2003, Personal persistence, identity development, and suicide: a study of native and non-native North American adolescents, Monographs of the Society for Research in Child Development, serial no. 273, vol. 68, no. 2 .

Department for Innovation, Universities and Skills 2008, A Vision for Science and Society: A consultation for developing a new strategy for the UK, July, Government of the United Kingdom, London, viewed 3 May 2010, <http:// webarchive.nationalarchives.gov.uk/tna/+/http://www.dius.gov.uk/ consultations/documents/A_Vision_for_Science_and_Society.pdf/>

Eckersley, R. 2004, Well \& Good: How we feel \& why it matters, Text Publishing, Melbourne.

Farfard, P. 2008, Evidence and Healthy Public Policy: Insights from health and policy sciences, May, National Collaborating Centre for Healthy Public Policy, Canada, viewed 3 May 2010, <http://www.cprn.org/documents/50036_ EN.pdf>

Freemantle, J., Officer, K., McAullay, D. and Anderson, I. 2007, Australian Indigenous Health - Within an international context, Cooperative Research Centre for Aboriginal Health, Darwin, viewed 3 May 2010, <http://www. crcah.org.au/publications/downloads/AustIndigneousHealthReport.pdf> 
Bridging the 'Know-Do' Gap

Landry, R., Lamari, M. and Amara, N. 2003, 'The extent and determinants of the utilization of university research in government agencies', Public Administration Review, vol. 63, no. 2, pp. 192-205.

Lehmann, D., Tennant, M., Silva, D., McAullay, D., Lannigan, F., Coates, H. and Stanley, F. 2003, 'Benefits of swimming pools in two remote Aboriginal communities in Western Australia: intervention study', British Medical Journal, vol. 327, pp. 415-19.

Mackenzie, D. and Chamberlain, C. 2003, Counting the Homeless 2001, Report prepared for Commonwealth Department of Family and Community Services, Australian Bureau of Statistics, Canberra.

Nutley, S., Walter, I. and Davies, H. 2007, Using Evidence: How research can inform public services, Policy Press, Bristol.

O'Donnell, M., Scott, D. A. and Stanley, F. J. 2008, 'Child abuse and neglect-is it time for a public health approach?', Australian and New Zealand Journal of Public Health, vol. 32, no. 4, pp. 325-30.

Rural Economy and Land Use Programme (RELU) 2007, Common Knowledge? An exploration of knowledge transfer, June, Rural Economy and Land Use Programme, UK, viewed 3 May 2010, <http://www.relu.ac.uk/news/ briefings/RELUBrief6\%20Common \%20Knowledge.pdf $>$

Sackett, D., Rosenburg, W., Gray, M., Haynes, B. and Richardson, W. 1996, 'Evidence based medicine: what it is and what it isn't', [Editorial], British Medical Journal, vol. 312, pp. 71-2.

Sanson, A. 2005, What can longitudinal studies tell us about supporting children's social and emotional wellbeing?, Paper presented at the Imagining Childhood: Children, culture and community Symposium, Charles Darwin University, Alice Springs, September.

Santrock, J. W. 2007, Child Development, Eleventh edition, McGraw-Hill Companies, New York.

Sawyer, M. G., Arney, F. M., Baghurst, P. A., Clark, J. J., Graetz, B. W. Kosky, R. J., Nurcombe, B., Patton, G. C., Prior, M. R., Raphael, B., Rey, J. M., Whaites, L. C. and Zubrick, S. R. 2001, 'The mental health of young people in Australia: key findings from the child and adolescent component of the national survey of mental health and well-being', Australian and New Zealand Journal of Psychiatry, vol. 35, no. 6, pp. 806-14. 
Schweinhart, L. J., Montie, J., Xiang, Z., Barnett, W. S., Belfield, C. R. and Nores, M. 2005, Lifetime effects: the HighScope Perry preschool study through age 40, Monographs of the HighScope Educational Research Foundation, no. 14, HighScope Press, Ypsilanti, Mich.

Silburn, S. R. 2009, Paper presented at the National Summit-Resilience for Children (0-13 years), Parliament House, Canberra, 16 June 2009.

Smart, D., Sanson, A., Baxter, J., Edwards, B. and Hayes, A. 2008, Home-toSchool Transitions for Financially Disadvantaged Children, The Smith Family, Sydney.

Spring, B. 2007, 'Evidence-based practice in clinical psychology: what it is, why it matters, what you need to know', Journal of Clinical Psychology, vol. 63, no. 7, pp. 611-31.

Stone, D. 2002, Getting research into policy, Paper presented at Global Development National Conference, Rio de Janeiro, 7-10 December.

The British Academy 2008, Punching our Weight: The humanities and social sciences in public policy making, a British Academy report, The British Academy, London, viewed 3 May 2010, <https://www.britac.ac.uk/policy/ punching-our-weight.cfm>

United Nations Children's Fund (UNICEF) 2007, Child Poverty in Perspective: An overview of child well-being in rich countries, Innocenti Report Card 7, UNICEF Innocenti Research Centre, Florence.

United Nations Children's Fund (UNICEF) 2008, The Child Care Transition, Innocenti Report Card 8, UNICEF Innocenti Research Centre, Florence.

Wood, J. 2008, Report of the Special Commission of Inquiry into Child Protection Services in NSW, Government of New South Wales through the Special Commission of Inquiry into Child Protection Services in New South Wales, Sydney, viewed 3 May 2010, <http://www.dpc.nsw.gov.au/publications/ news/stories/special_commission_of_inquiry_into_child_protection_ services_in_new_south_wales $>$

Zubrick, S. R., Silburn, S. R., Lawrence, D. M., Mitrou, F. G., Dalby, R. B., Blair, E. M., Griffin, J., Milroy, H., De Maio, J. A., Cox, A. and Li, J. 2005, The Western Australian Aboriginal Child Health Survey: The social and emotional wellbeing of Aboriginal children and young people. Volume 2, Curtin University of Technology and Telethon Institute for Child Health Research, Perth, viewed 3 May 2010, <http:/www.ichr.uwa.edu.au/waachs/publications/ volume_two> 